\title{
Challenges Faced By Brand Managers in the Luxury Industry: Attitudes and Motivations of Luxury Clothing Consumers
}

\author{
Valentina Iuliana Diaconu and Mădălin Lucian Cerceloiu
}

University of Economic Studies, Bucharest, Romania

Correspondence should be addressed to: Valentina Iuliana Diaconu;

valentina.iuliana.diaconu@gmail.com

Received date: 19 January 2017; Accepted date: 19 April 2017; Published date: 12 June 2017

Academic Editor: Elena Stanislavovna Kiseleva

Copyright (C) 2017. Valentina Iuliana Diaconu and Mădălin Lucian Cerceloiu . Distributed under Creative Commons CC-BY 4.0

\begin{abstract}
The luxury fashion industry is going through a continuous development at an international level. The growth that was registered by the industry after the recession was determined by the urbanization degree, the internationalization of luxury brands, the decline of the wholesale market, the different consumption types that millennials have, the growth within the market segment that addresses consumers through the development of products that target their needs, the development of new retailers, the growth in existing store chains, but also technological development. The beauty industry will double itself in years to come and the main players within this market will be China, the US, Brazil, India and Japan (Bain \& Company, 2014). The online medium represents the perfect space to promote high end products and this can be seen observed to the fact that consumers upload dozens of selfies with their favorite products on a daily basis, or watch videos that offer them advice on style matters. With these aspects in mind, the article is based on a qualitative research regarding attitudes and motivations of luxury clothing consumers with the purpose of understanding the behavior of the luxury clothing consumer and the attributes that determine the purchase or the nonpurchase of such products.
\end{abstract}

Keywords: motivation, attitude, consumer behavior, brand, luxury market.

Cite this Article as: Valentina Iuliana Diaconu and Mădălin Lucian Cerceloiu (2017), " Challenges Faced By Brand Managers in the Luxury Industry: Attitudes and Motivations of Luxury Clothing Consumers ", Journal of Marketing Research and Case Studies, Vol. 2017 (2017), Article ID 770239, DOI: 10.5171/2017. 770239 


\section{Introduction}

The luxury clothing industry is an industry that is characterized by a high level of competitiveness and dynamism, where brand managers are faced with numerous decisions and challenges.

Surely, one of the biggest challenges that brand managers face in the luxury clothing industry is accessing and deciphering the information from within the consumer's socalled "black box", in order to gain a perspective into the consumer's behavior. Investigating the consumer's attitudes and motivations can prove to be an important challenge for the brand manager to face. The article tries to offer insight regarding consumer attitude and motivation and the way they influence the consumer's behavior.

\section{Consumer Behavior through Attitude and Motivation}

Along with the development of the field that studies consumer behavior, the majority of specialists agree that both attitude and motivation represent two intrinsic elements of consumer behavior, elements that require continuous study in order for marketers to unlock the consumer's "black box". The notion of consumer behavior, a concept that emerged in the 40's within a background of a shift from a philosophy geared toward sales to one that is focused on the concept of marketing, has become a field that is intensely studied in present time, due to a rise in competitiveness within the market (Kardes, Cronley \& Cline, 2008).

Characterized by specialists as being a multidimensional concept, consumer behavior is the result of a system of dynamic relations between the processes of perception, information, attitude, motivation and effective manifestation (Cătoiu \& Teodorescu, 2004). In an effort to study consumer behavior, marketers can approach each one of these processes in order to have a better perspective on consumer behavior. The two processes that are broached by this article are attitude and motivation. Although attitude was a concept initially defined through a psycho-sociological approach as being a mental or neural state of promptitude, organized through experience and exerting a dynamic influence on an individual's response regarding all objects and situations in regards to the said individual (Allport, 1935), it has been integrated within consumer behavior and within marketing. The link between attitude and consumer behavior has been theorized and illustrated through a series of cognitive models by consumer behavior specialists (Howard, Sheth, 1969). According to Hawkins (2001), attitude places itself among the internal psychological factors that influence consumer behavior. A classification of the functions that attitude has is propposed by Solomon (2012), namely utilitarian function, value expressing function, ego defensive function and knowledge function. The utilitarian function deals with the attitudes that were formed as a response to using a certain product, as a reward/punishment type of response. The value expressing function has to do with the way in which the consumer percieves him or herself and the need to express themselves. The ego defensive function deals with the defensive attitude due to the consumer's needs to defend himself from external or internal factors. The knowledge function appears when the consumer needs structure and order.

Hawkins and Mothersbaugh (2010) offer three basic components of attitude: the cognitive component, the affective component and the behavioral component. According to the model propposed by the same specialists, the cognitive component deals with the product's attributes or the product as a whole, the affective component is linked with the feelings and emotions towards the product's attributes and the behavioral component deals with de behavioral intentions in relation to the attributes or the product. The same notions can be found at Solomon (2012) structured 
within the ABC model (acronym for Affective, Behavioral, Cognitive), where he states that the model is based on three core notions - to feel, to act, to know.

Motivation, from a marketing standpoint, is a key-element within consumer behavior. Motivation can be found within the psychological factors that influence consumer behavior (Kotler, 2014). Motives reside at the base of the buying behavior, representing a resulting element of a biological, physical or social nature (Cătoiu \& Teodorescu, 2004). Motivation appears, like attitude, within cognitive models as being an essential building block of consumer behaviour (Nicosia, 1966).

Specialists in the field consider that motivation is closely linked with needs and the state of tension that is created by needs. Furthermore, needs can be hedonistic or utilitarian (Solomon, 2012).

Motivation can be characterized through the strength that it exerts on the consumer but also through their direction, specifically the way in which the consumer acts. Motivation can also have a positive or a negative valence, each of the two contributing and influencing the consumer's behavior (Solomon, RusselBennett \& Previte, 2013).The article tries to offer a study regarding consumer behaviour through attitudes and motivations that determine the purchase or non-purchase of luxury clothing products.

\section{Challenges That Brand Managers Face Within the Luxury Industry}

According to studies, marketing specialists tend to invest approximately $80 \%$ of their budget on existing clients and $20 \%$ on gaining new customers. Depending on the campaigns they conduct, brand managers can analyze what the loyalty rate within consumers is and how the consumers react to loyalization programs or the rewards offered at a certain purchase amount (Emarketer, 2015). Loyalization campaigns based on gifts or price drops are not always the best ways of increasing profitability or growing a brand, but a clean image, spot-on merchandising, an impeccable store ambience or the professionalism of brand ambassadors or frontline employees can bring the highly sought after results from investments in marketing. Following all these elements, the brand manager's challenge is to attract consumers to luxury brands in a way in which they return to the store after they have purchased out of curiosity or experimentally purchased and become loyal users. How should luxury industry companies face such situations? Firstly, improvements can be made to the relationship that they have with their clients through a superior consumption experience, a feat that can be achieved through the creation of a campaign that promotes a clear message, a message that is correctly targeted through innovation at a marketing level but also through the omnichannel strategy (itespresso, 2016). From a commercial and a brand management point of view, the omnichannel is an evolution of the multichannel, due to the fact that it requires the simultaneous use of a number of channels that are well optimized, being at the same time an answer to the expectations and changes of consumers that become omniconsumers. Here we can note the fusion of brick-to-click practices (the technologization of offline stores) with the click-and-collect practices and content marketing through the influencing of the purchase decision by campaigns created by marketers (IGD, 2015). Secondly, the image and retail policy must respect the highest standards and develop a culture of hospitality, offering the best assortment of products so that the client's needs be satisfied and surpassed, because a luxury consumer is always expecting a purchase experience that surpasses his or her expectations. On the other hand, people's excellence is essential in developing a luxury brand, thus one must ensure talent management, a good engagement from the team that interacts directly with the clients, but also a better orientation toward clients 
(Bain \& Company, 2014). Furthermore, the excellence of the people from the first line can be improved through a mystery shopper program that can be organized annually or semesterly so that it permits the removal of obstacles that prevent people from overcoming their limits in regards to the relationship with the client. Evaluation and control make for a superior quality of purchasing services or post-sale services not only in companies within the luxury industry, but also in companies that deal with general consumer goods. A study by Luxury Institute reveals that brands like Burberry or Bottega Veneta grow, unlike other brands, because they invest heavily in personnel and frequently use mystery shopper programs that help employees develop, becoming more enthusiastic with the experiences that they have with their customers within brand stores (Luxury Institute, 2011). Along all the previously stated elements, a strong degree of visibility must be maintained within the online medium, but also keeping a close relationship with users through social media. Socializing sites can be a real support in taking marketing decisions, because consumers often talk about luxury brands on social media when they are content but especially if they are discontent with a respective brand (KurtSalmon, 2016). Beside the classic website, brands should be as active as possible on platforms such as Instagram, Youtube, Twitter or Snapchat.
Based on opinions of social media users, one can build an analysis of the feelings and emotions the consumers have in order to measure the impact that they have on a luxury brand, but also construct a specifically tailored strategy to fit the newly-discovered needs of consumers. Listening to the consumers and correctly analyzing the statistical information resulting from social media can determine the elements that the brand can improve. These can be applied to the product policy, in deciding product range, in setting correct competitive prices, aligned to the superior quality of luxury products. All of these things can lead to image improvement and help maintain a desired image on a long term basis so that any negative perception be eliminated from the consumer's mind.

\section{Conceptual Model and Hypotheses}

The qualitative study that was conducted revealed a series of aspects regarding the behavior of luxury clothing behavior that can be analyzed by brand managers through attitudes and motivations. The objective of this exploratory research was the identification of variables that influence the purchase or non-purchase of luxury clothing items, variables for which a cognitive model has been constructed in order to show a series of functional and causal relations. 


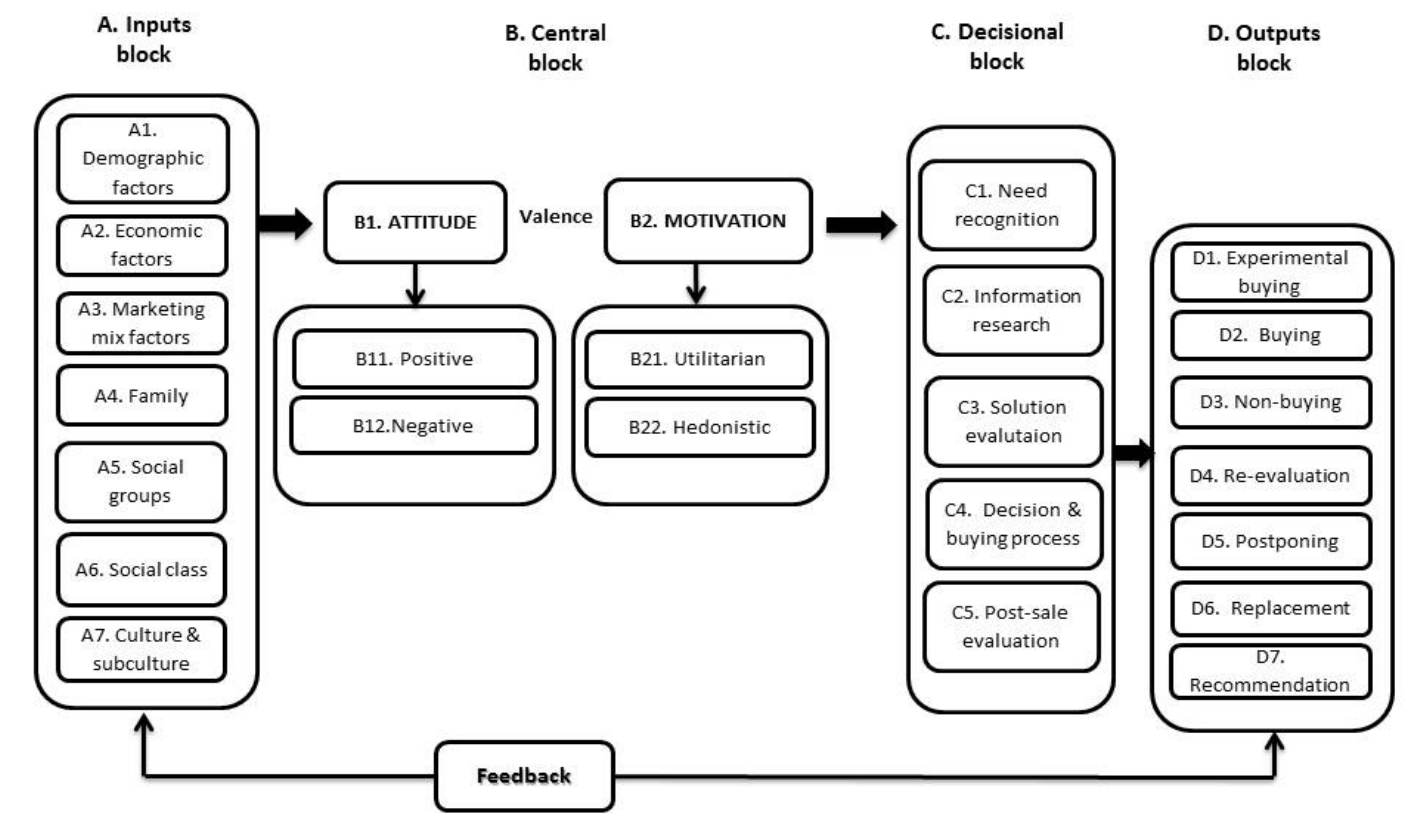

Source: Made by the authors

\section{Fig 1: Cognitive analysis model of consumer behavior through attitudinal and motivational variables that influence the purchase or non-purchase of luxury clothing products}

The cognitive model that can be seen in Figure 1 is composed of four blocks: inputs, central unit, decisional block and outputs. The inputs block contains a series of factors that influence the behavioral variables, attitude and motivation, directly or indirectly. These factors are determined by demographic factors, economic factors, marketing mix factors, family, social groups, social class and culture and subculture. Consumers are heavily influenced by factors of an exogenous nature, that once passed through the thought filter correlated with endogenous factors (memories, personal experience) converge on either a purchasing or a non-purchasing behavior (Kotler \& Keller, 2006). The central unit is determined by attitude and motivation, followed by the decisional block that determines the purchase or the non-purchase of luxury clothing articles. In the case of luxury products, attitude towards them plays an important part because this type of goods is characterized by exclusivism, superior quality and high prices, fact that can determine a positive image for existing users or a negative image for people that wouldn't desire to wear such items (Silverstein, 2003). The last block contains the options that the individuals can have in mind, whether they are on the first purchase, or they are postponing the purchase or end up recommending the purchased product or the luxury brand to others. The article also broaches two types of motivation: hedonist motivation, determined by excitement, fun, emotion, pleasant memories; and utilitarian motivation, characterized by the functionality of luxury clothing products. The relations that are established between attitude, motivation and the rest of the variables within the discussed cognitive model are of two types: functional or causal. The functional relations are represented by the group of independent variables $y=f(x)$, that satisfy the same conditions for the discussed problematic. For example, functional relationships can be established 
between the variables from block A - Inputs. On the other hand, causal relationships are exerted by the influence of an $X$ characteristic on another $\mathrm{Y}$ characteristic, $\mathrm{x} 1$ $+\mathrm{x} 2 \rightarrow \mathrm{Y}$. Such a relation can be established between the positive attitude towards a luxury clothing product, the desire for prestige or the effective purchase. All of these relations can be synchronous or asynchronous (Yule \& Kendall, 1969). Following the relations that can be established between the variables within the cognitive model that was elaborated, it can be concluded that brand managers, in an effort to reach their objectives, can follow the elements that are the most profitable and advantageous on the long term.

\section{Research Results}

The qualitative research on which the article is based was conducted through a number of 32 in-depth interviews with both male and female respondents, ages between 21 and 60, that work in fashion or fashion-related industries. The individual discussions presented a series of variables that can influence the buying behavior or non-buying of luxury clothing products. The results of the qualitative study revealed a generally positive attitude toward luxury clothing articles, considered by respondents as being modern, inspirational, exclusivist, expensive and being of high quality. Among the respondents that had a negative attitude were the ones that can not afford these types of goods, the ones that do not have a defined fashion style, the ones that don't consider that the events they attend are important, the ones that don't consider their personal image as being of importance and the ones that don't consider fashion as being indispensible. A positive attitude determines a positive motivation that further on influences the buying behavior and the recommendation to other users. On the other hand, a negative attitude is caused by experiences, bad personal memories or is transmitted by other individuals, fact that causes a non purchase behavior, the return of the product or reevaluating the purchase. The content analysis of the qualitative research revealed a series of motivations that are more or less visible, but can influence the purchase behavior of luxury clothing products: the desire for uniqueness and exclusivism, the desire for power and status, the durability of materials and colors, innovation and product design, the desire to wear high quality clothing, admiration for famous brands, pleasant memories and the existence of an inspirational role-model within the family or outside of it, the desire to set trends, education and chosen culture, the desire to learn and find the right style, curiosity and the desire to impress others, the desire for fun or the desire for a luxurious lifestyle, the workplace and the activities that impose the utilization of luxury products. In the same time, non-purchase motivations were shown through elements such as: high price, snobbism, the disgust toward the people that wear luxury clothing, inaccessibility, the reduced or exclusive distribution, the lack of events that require wearing high-end articles, bad experiences regarding a visit to a luxury boutique, the lack of utility of a luxury textile product, the lack of knowledge regarding luxury brands, the sub appreciation of the luxury industry, but also an inferior degree of education or culture.

Furthermore, along with in-depth interviews, two new instruments have been tested, instruments that analyze voice tone and the emotions belonging to respondents. The participants' voice tonality during the indepth interviews has been analyzed with the help of a computer-based instrument, IBM Watson Developer Cloud - Tone Analyzer. This instrument helped in the identification of a series of motivations and attitude that were hidden within the participants' nonverbal communication. The second computer-based instrument that was used for the analysis was AlchemyAPI, a program that uses the processing of natural language, artificial intelligence, deep learning, being capable of analyzing written text, from which unstructured data have been extracted. The investigated answers from the study analysis at hand revealed a series of attitudes and 
motivations that determine the purchase or non-purchase of luxury clothing. If attitude can be easily detected within a non-verbal language, in the case of motivation, the visibility is slightly reduced. Nonetheless, motivations have been established through a series of projective exercises meant to determine the respondents to freely express their opinions without feeling constrained, as would be the case of a statistical survey that has a standardized and unfriendly structure. The projective techniques that were used were then accompanied by the utilization of digital instruments that analyzed the emotions that were conveyed through the respondents' answers. The exercises and case studies that were created to be used during the in-depth interviews revealed a generally positive attitude toward luxury and luxury clothing articles. Both positive and negative attitudes manifested themselves from three different perspectives: affective, cognitive and behavioral (Rosenberg \& Hovland, 1960; Krech, 1962). The affect was observed either when it came to the adoration of a luxury clothing product or brand, or from the love or attachment regarding a close person. On the other hand, the affective component also manifested itself in the opposite direction, along with feelings like hate, pride, discrimination, prejudice, fear, uncertainty, disgust, guilt toward people that can not afford expensive clothes, addiction, shame, vulgarity, poverty, loneliness, disappointment, indifference or the feeling that they don't deserve the good. The cognitive attitude based itself on a logical rationale through which the individual that judges both the functional attributes and the aesthetic attributes that the luxury article offers. The conative, or behavioral attitude was determined by a series of actions that the respondents listed during the interviews: gathering information regarding trends or luxury locations, planning and organizing the visit to a store, trying on luxury clothing, interacting with store personnel, the search for information online - information provided by specialists or by influencers, experimental purchase, non-purchasing, reevaluation, returning and changing of products, postponing the decision or recommending to users (LaPiere, 1934). Regarding the motivational aspect that was addressed in the article, its manifestation was different during the utilization of the computerized instruments. Thus, among the most mentioned motives during the discussions were: the seeking of refinement, the display of elegance and the strive for personal prestige, which means that when individuals choose to utilize a luxury clothing product they are influenced by a certain style, by a feeling of prestige and renown, respectively the display of refinement that is cultivated in time through a superior education or experiences that were accumulated through the decision making process.

The IBM Watson Developer Cloud - Tone Analyzer application permitted the analysis of the impact that the respondents' tone of voice had when they were allowed to express their perception and ideas in regards to the consumption of luxury clothing products. The analysis of the impact of voice tonality can constitute an emotional factor of influence in identifying hidden motivations related to the utilization of luxury clothing products. Although an individual can transmit a positive statement, the tone that is used can indicate a state of nervousness, passiveness or uncertainty; the same thing can be true in the case of a negative statement, fact that helps in identifying or discovering attributes that are less visible in consumer behavior. An example of transmitted message by one of the respondents during individual discussions and the analysis that resulted after the use of the cloud:

"Fashion is something indispensible, o woman or a man must find her or his own style through which they can stand out and gain recognition from others."

Tone Analyzer application extracted from this phrase the respondent's predominant feeling when talking about luxury fashion is that of anger, with a low to medium intensity. The respondent has an awareness of this feeling, which can suggest the fact that this 
respondent is discontent with the social pressure caused by fashion, pressure that constrains through social recognition of the individual style. In a world characterized by continual change, personality and individual pride can be affected if they are not sustained by a certain financial condition or a certain education. Furthermore, another type of consumer that uses luxury clothing can be identified only because of the influence of social tension and the desire to fit into a certain social group. At a careful analysis of the transcription of the participants' responses to the study, the term fashion appears to be a keyword, being frequently used, which can translate into a positive feeling related to this field, having a score of 0.66 and with a 0.93 relevance indicator, measured with the AlchemyAPI application.

With this information in mind, it can be deduced that the attitude and the motivation that can influence the buying or non-buying behavior of luxury clothing products are not dependent only on the variables that belong to income, education or influence from others, but rather they are correlated with memories and experiences that they had during one or more previous decision processes. Furthermore, when it comes to luxury, attitudes can be treated through the perspective of affect, cognition and conation, while motivations of a hedonist nature are responsible for happiness, pleasure, general euphoria, fun or pleasant memories. Thus, consumers can be influenced by a series of endogenous or exogenous factors, the purchase or non-purchase decision belonging only to them. The marketer's challenge resides in finding the most profitable mode in which to attract individuals toward the chosen brand, a brand to which they remain loyal consumers.

\section{Behavioral Differences Between Men and Women Consumers}

Even in ancient times, fashion was not a foreign concept to people's daily lives. Fashion was a means in which people could express their personality and individuality, their cultural origins and social status. Even though these types of products were limited, their utility as simple garments was to cover the human body and shield them of external factors, nowadays the concept is at a whole new level.

Respondents that took part in individual discussions were both female and male, each of them having their own personal vision on luxury and fashion due to their personally achieved degree of culture, their income, the social environment in which they live, their own history of consumption when it comes to exclusive goods, their place of work and the influence from their friends, but also the influence from marketing. Some respondents are predisposed to change, to trying on a brand that is new to the market, while others are not willing to inform themselves or to try something different than what they're currently using. At the same time, a certain degree of knowledge or education regarding fashion, art or other adjacent fields has delimited three categories of individuals that consume luxury products: connoisseurs, amateurs and inexperienced. From the participants, women turned out to be more knowledgeable when it comes to luxury brands, trends or social events, aspect that indicates the fact that they are preoccupied with their image and their development. Women know the concept of luxury, have high expectations when it comes to quality, usually have a role model and are brave through their inclination for modernity and extravagance. The men that took part in the study stated that they focus on a brand or two when choosing to buy clothes. They are much more conservative and prefer styles that are strongly masculine and elegant. 


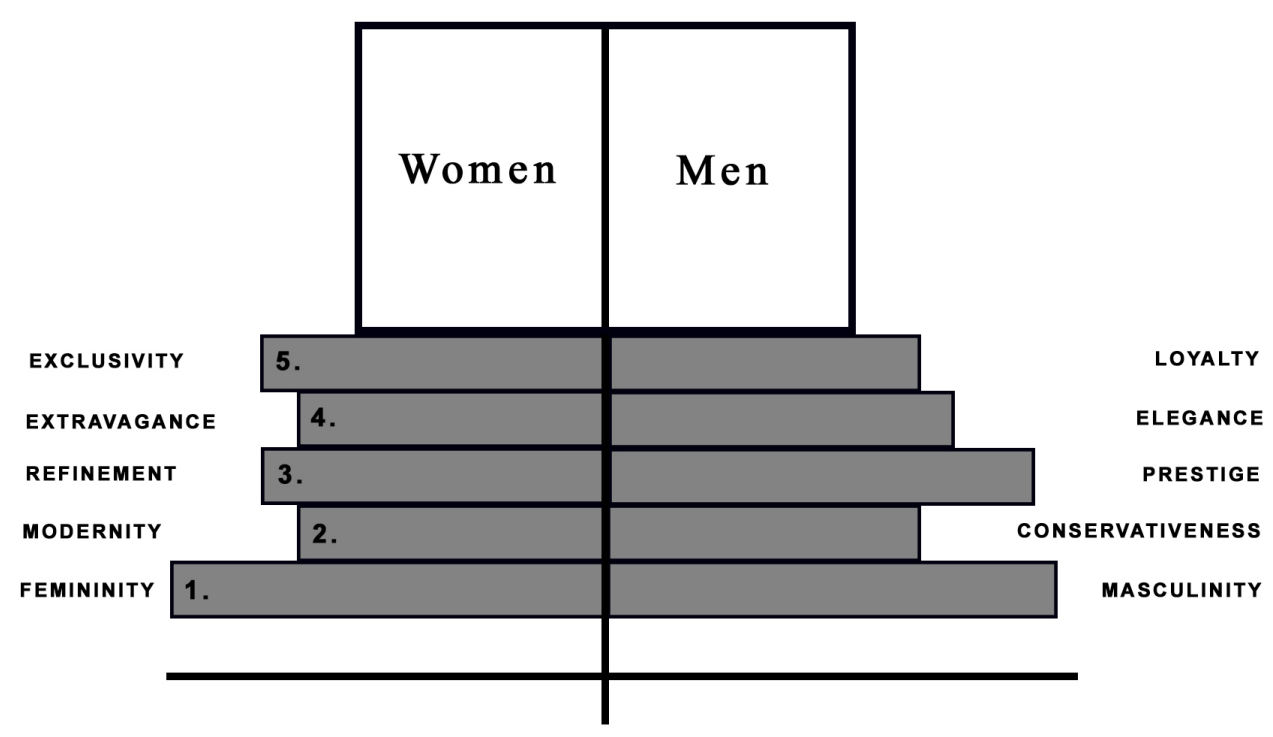

Source: Made by the authors

Fig. 3: The scale of motivation for the purchase of luxury clothing for women and men

According to the above graph, 5 main attributes have been established as a result of the analysis of the in-depth interviews. These 5 main attributes can constitute motivations that determine the purchase or non-purchase of luxury clothing objects. For women, the 5 most important motivations were: Femininity, Modernity, Refinement, Extravagance and Exclusivity - elements that reiterate what was previously presented. The motivations for men were: Masculinity, Conservativeness, Prestige, Elegance, Loyalty; unlike in the case of women, men turned out to be pragmatic users, because the things that they have in mind are attributes such as efficiency and practical utility when it comes to luxury articles. Thus, starting from the two categories, women and men, two visions can be deduced, visions that delimit the universe of luxury: modernity together with extravagance and tradition coupled with prestige.

\section{Luxury Fashion Retailer's Approach}

The luxury fashion industry is characterized by high costs that cover everything from location-related expenses, personnel or brand promoting to investment in new technologies. All of these elements lead to improvement in customer relations and the improvement of the brand's image. The image that the consumer creates in his or her mind is the key factor that most of the times can form spontaneously. The mature consumer is trustful and knows what are the attributes that he or she must appreciate in a luxury clothing product; this consumer understands the market and appreciates the loyalizing systems used by retailers. A young consumer, a novice when it comes to the luxury industry can be educated toward a new consumer behaviour, but it may prove difficult to loyalize toward a certain brand. As it has also been demonstrated in the content analysis of the qualitative research, consumers tend to identify themselves with their favorite brand and tend to associate behavioral traits with elements that are offered by the brand through "signaling" (McKay, Mijović, Prelec, 2011). This term shows that a product or a brand may possess certain attributes that attract the attention of potential consumers in a more subtle or a more obvious way. The mentality of people who purchase luxury products is tightly related to the value that a luxury brand has, to the synergy of the intangible elements that 
this value offers (history, art and mastery of the stitching, the privileged status, uniqueness, country of origin etc.)

It must be stated that a business within the field of fashion is completely different from other businesses because clothing items are short-lived goods, created as a result of trends and as a result of the vision of its creator or designer. Based on the results that were obtained, a "Decalogue" of basic competencies for sellers in the luxury industries can be built. Some of these competencies are:

1. Offering high quality unique products and services

2. Attracting and maintaining talented and involved personnel

3 . Deep knowledge of the luxury market and business oriented view

4. Concentrating on key products and collections

5. Constant consumer research

6. Omnichannel distribution

7. Disruptive marketing

8. Excellence in commercial and operational performance

9. Creating a personalized luxury experience and paying attention to detail

10. Offering dual-gender products and services

The results of the qualitative study regarding luxury fashion consumer attitudes and motivations can be expanded upon in a future quantitative research in which luxury consumer behavior can be investigated. It is important to identify the key-factors that determine the type of relation between the luxury brand and luxury clothing users. A strong positive relationship can contribute to creating a legacy for the brand on the luxury market. This type of relationship can be built in specialized stores where sales forces can make a difference. An experienced salesman can approach a potential buyer just by observing his or her nonverbal behavior and can offer the best service without causing a disturbance (Puccinelli, Goodstein \& others, 2009).

\section{Conclusions}

The challenges that brand managers face in the luxury industry are strongly influenced by the ever-changing consumer behavior. Individuals' attitude and motivation directly influence the purchase or non-purchase behavior for luxury clothing products, and this thing was determined through the functional and causal relations shown in the created cognitive model and demonstrated through the 32 in-depth interviews that were conducted with specialists in the field of fashion or other adjacent fields. The qualitative research that was conducted identified a generally positive attitude toward luxury fashion but also motivations such as: the desire for uniqueness and exclusivism, the desire for power and status, memories and pleasant experiences, the desire to learn and find one's own style, curiosity, fun and the desire to have a luxurious life, the fear of embarrassment and so on. Visible differences between women and men resulted in two visions regarding the consumption of luxury clothing products: one is a modernist vision and refers to the courage to try on brands that are new to the market, clothes with an innovative design, lacking a practical utility; the other vision is oriented toward tradition, loyalty to one or two brands that produce clothes that are always "in fashion". In conclusion, starting from these results the barriers that prevent the luxury brand to become more visible and prevent marketing budgets to be redirected to campaigns that have a bigger return on investment rate can be overcome. Furthermore, the results that have been obtained can help in offering a base for better understanding of the consumer behavior when it comes to luxury clothing, a better understanding of the motivations behind the purchase of such goods and of the attitudes toward luxury fashion and the ways in which the relationship between customer and the luxury brand can be improved. 


\section{References}

1. Allport, G. W., 1935, Handbook of social psychology, MA: Clark Univ. Press, Worcester, 734.

2. Cătoiu, I., Teodorescu, N., 2004, Consumer Behavior, Editura Uranus, București.

3. Howard, J. A., Sheth, J. N., 1969, The Theory of Buyer Behavior, Wiley, New York.

4. Hawkins, D.I., Best, R.J., Coney, K.A., 2001 Consumer behavior, $8^{\text {th }}$ Edition, McGraw-Hill, New York.

5. Hawkins, D., Mothersbaugh, D., 2010, Consumer Behavior: Building Marketing Strategy, 11th Edition, McGraw-Hill/Irwin, New York.

6. Kardes, R. F., Cronley, L. M., Cline, W. T., 2010, Consumer Behavior, South Western Educational Publishing, Mason.

7. Kotler, P., Keller, K. L., 2011, Marketing Management, $14^{\text {th }}$ Edition, Prentice Hall, New Jersey.

8. Kotler, P.T, Keller, K. L., 2006, Marketing Management, Prentice Hall, 12th edition, London.

9. LaPiere, R. T., 1934, Attitudes vs. Actions, Social Forces, 230-237.

10.McKay, R., Mijović-Prelec, D.; Prelec, D., 2011, Protesting too much: Self-deception and self-signaling, Behavioral and Brain Sciences. 34 (1): 34-35. doi:10.1017/S0140525X10002608. ISSN 1469-1825.

11.Nicosia, F. M., 1966, Consumer Decision Processes, Prentice Hall, New Jersey.

12.Puccinelli, N. M., Goodstein, R. C., Grewal, D., Price, R., Raghubir, P., Stewart, D., 2009, Customer Experience Management in Retailing: Understanding the Buying Process, Journal of Retailing 85, 15-30.
13.Silverstein, M., Fiske, N., 2003, Luxury for the masses, Harvard Business Review, 10-11.

14.Solomon, M. R., Russel-Bennet, R., Previte, J., 2013, Consumer Behaviour: Buying, Having, Being, Pearson Australia, $3^{\text {rd }}$ Edition, 138.

15.Solomon, R. M., 2012, Consumer Behavior: Buying, Having and Being ,10 $0^{\text {th }}$ Edition, Prentice Hall, New Jersey.

16.Yule, G. U., Kendall, M., 1969, An Introductin to the Theory of Statistics, Ed. Stiintifica, București.

17.http://www.itespresso.fr/strategiedistribution-omnicanal-magasin-resistance131165.html [accessed on the $11^{\text {th }}$ of July 2016]

18.http://www.kurtsalmon.com/global/Reta il/vertical-capability/440/Leveraging-SocialListening-Insights-Across-the-Retail-

Enterprise [accessed on the $11^{\text {th }}$ of July 2016]

19.https://www.emarketer.com/public_med ia/docs/eMarketer_Report_Loyalty_Marketin g_Creating_Stickiness_in_a_Distracted_World. pdf [accessed on the $20^{\text {th }}$ of July 2016]

20.http://www.igd.com/Research/Economic s--horizon-scanning/ [accessed on the $20^{\text {th }}$ of July 2016] https://www.luxurydaily.com/59pc-ofconsumers-would-rather-shop-at-brandsstore-than-department-stores/ [accessed on the $21^{\text {th }}$ of July 2016] 